\title{
Vitrectomy with Internal Limiting Membrane Peeling with Intravitreal Ranibizumab Injection for Patients with Central retinal Vein Occlusion with Combined Epiretinal Membrane
}

\author{
Mahmoud Mohammed Ahmed Ali ${ }^{1}$ MD
}

\author{
*Corresponding Author: \\ Mahmoud Mohammed Ahmed Ali \\ Drkhali12020@yahoo.com
}

Received for publication May 11, 2021; Accepted July 23, 2021; Published online July 23, 2021.

Copyright The Authors published by Al-Azhar University, Faculty of Medicine, Cairo, Egypt. Users have the right to read, download, copy, distribute, print, search, or link to the full texts of articles under the following conditions: Creative Commons AttributionShare Alike 4.0 International Public License (CC BY-SA 4.0).

doi: $10.21608 /$ aimj.2021.76085.1474

${ }^{1}$ Ophthalmology Department, Faculty of Medicine, Al-Azhar University, Cairo, Egypt.

\begin{abstract}
Background: Central retinal vein occlusion (CRVO) is one of the most common causes of visual loss in general population especially in middle age and elderly people.

Aim of The Work: To assess the role of vitrectomy with internal limiting membrane (ILM) peeling with intravitreal ranibizumab injection for patients with CRVO with combined epiretinal membrane (ERM).

Patient and Methods: The study was conducted on eleven patients with CRVO with coexisting ERM. Best corrected visual acuity (BCVA) converted into $\operatorname{logMAR}$, fundus Fluorescein angiography and optical coherence tomography (OCT) assessing central macular thickness (CMT) were done. All patients had undergone vitrectomy with ILM peeling with intravitreal injection of ranibiaumab $(0.5 \mathrm{mg} / 0.05 \mathrm{ml})$. Postoperatively, the patients were examined 1 week and 1 month for BCVA in logMAR and full ophthalmic examination. Also, OCT was done one month postoperatively.

Results: There was a significant decrease in one week $(1.064 \pm 0.258)$ and four weeks $(0.718 \pm 0.316)$ postoperative BCVA in log Mar than preoperative BCVA (1.245 \pm 0.221$)$. Also, there was a significant reduction in the four-week postoperative CMT $(357.73 \pm 133.094)$ than preoperative CMT $(497.27 \pm 225.420)(P=0.003)$.

Conclusion: Vitrectomy combined with ILM peeling with intravitreal ranibizumab injection showed anatomical efficacy for macular edema (ME) in eyes with CRVO associated with ERM. Also, BCVA improved significantly concurrently.
\end{abstract}

Keywords: Central retinal Vein Occlusion; Vitrectomy; Internal Limiting Membrane Peeling; Ranibizumab; Epiretinal Membrane.

Disclosure: The authors have no financial interest to declare in relation to the content of this article. The Article Processing Charge was paid for by the authors. Authorship: All authors have a substantial contribution to the article.

\section{INTRODUCTION}

Central retinal vein occlusion (CRVO) is one of the most common causes of visual loss in general population especially in middle age and elderly people. There are two types of vein occlusion, ischemic and non ischemic. ${ }^{1}$

The main complications of CRVO are cystoid macular edema (ME), ocular neovascularization and vitreous hemorrhage. ${ }^{2}$ Cystoid macular edema may lead to severe visual loss the treatment of which depends mainly on anti-VEGF injections. ${ }^{3}$

Epiretinal membranes (ERM) are formed by cellular migration and proliferation over the vitreoretinal interface. One of the causes of secondary ERM is retinal vein occlusion. ${ }^{4}$

Anti VEGF injection can cause vascular endothelial cells hypoxia and increase connective tissue expression which might lead to tissue fibrosis and epiretinal membrane proliferation. ${ }^{5}$ Also, ERM works like a barrier leading to a decrease in anti VEGF penetration. ${ }^{6}$

Depending on the above data, the usual regimen in management of CRVO represented in anti-vegf injections mayn't be efficient in patients who have also combined ERM or even may lead to aggravation of ERM with finally fewer visual outcomes. This study discusses the role of vitrectomy with internal limiting membrane (ILM) peeling with intravitreal ranibizumab injection in patients with CRVO with combined ERM.

\section{PATIENTS AND METHODS}

A prospective cohort study conducted at Ophthalmology Department, Al-Azhar university Hospital, Egypt during the period from August 2019 till December 2020 and involved eleven patients with central retinal vein occlusion with coexisting ERM.

All participants enrolled in the research were given written consent. The approval of the research was achieved from Al-Azhar Faculty of Medicine (Research Ethics Committee (REC).

Eyes with vitreous hemorrhage, dense cataract, vitreomacular traction, previous vitreoretinal surgery, previous macular grid laser photocoagulation, uncontrolled glaucoma and other ocular lesions that could cause a decrease in vision were excluded from the study. 


\section{Methods:}

preoperatively, all participants had undergone ophthalmic assessment involving BCVA converted to $\operatorname{logMAR}$, anterior segment examination and fundus examination.

Fundus Fluorescein angiography and OCT assessing central macular thickness were done.

Postoperatively, the patients were examined 1 week and 1 month for BCVA in logMAR and full ophthalmic examination. OCT was done one month postoperatively.

\section{Vitrectomy technique:}

All participants underwent a standard 23 gauge vitrectomy, starting with insertion of three trocars, after that core vitrectomy was done then vitreous staining with triamcinolone acetonide followed by posterior vitreous detachment induction, then ILM staining using Brilliant Blue G together with ILM peeling reaching the vascular arcades (figure 1), then complete shaving, then pan retinal photocoagulation (PRP) (figure 2) and finally ranibizumab injection $(0.5 \mathrm{mg} / 0.05 \mathrm{ml})$ through the trocar leaving the patient without tamponade with massaging on sclerotomies

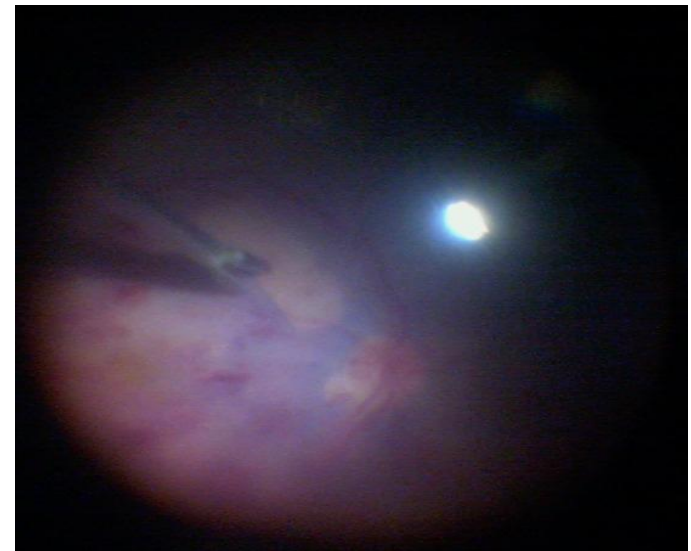

Fig. 1: Internal limiting membrane peeling

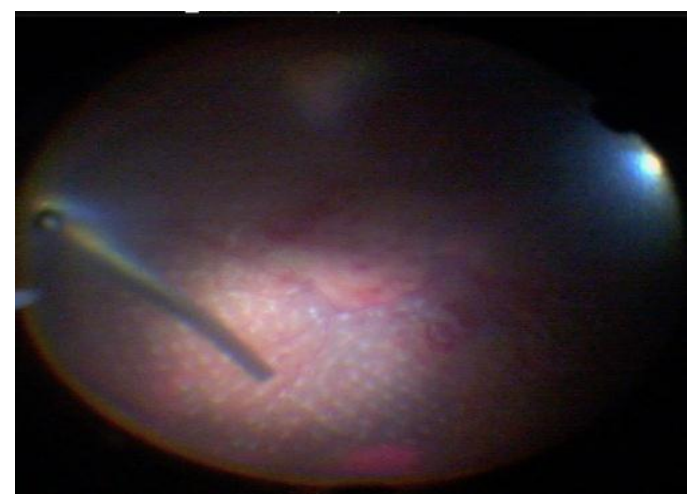

Fig. 2: Panretinal photocoagulation.

\section{Statistical analysis:}

Statistical Package for Social Sciences (SPSS) (version 23.0, IBM, Armonk, NY) was used to analyze data of the study. According to the type of data qualitative represented as number and percentage, quantitative represented by mean \pm SD and comparison between groups was done by using Wilcoxon Test (Z). Level of significance was at $\mathrm{p}<$ 0.05 .

\section{RESULTS}

A total of 11 eyes of 11 patients with central retinal vein occlusion with coexisting ERM were involved. Four eyes belonged to males $4(36.4 \%)$ and Seven eyes belonged to females $7(63.6 \%)$. Their age ranged from 30 to 73 years with a mean of $58.27 \pm 12.83$. The eleven eyes were 7(63.6\%) right, and 4(36.4\%) left (Table 1).

\begin{tabular}{|c|c|c|}
\hline Parameter & Frequency & Percent \\
\hline Age & \multirow{2}{*}{\multicolumn{2}{|c|}{$(30-73)$}} \\
\hline Range & & \\
\hline Mean \pm SD & \multicolumn{2}{|c|}{$58.27 \pm 12.83$} \\
\hline Gender & & \\
\hline Male & 4 & 36.4 \\
\hline Female & 7 & 63.6 \\
\hline Eye side & & \\
\hline Right & 7 & 63.6 \\
\hline Left & 4 & 36.4 \\
\hline
\end{tabular}

Table 1: Demographic data of patients

Regarding co-morbidity, there was ten patients (90.9\%) had hypertension and two (18.2\%) had diabetes mellitus (Table 2).

\begin{tabular}{|c|c|c||}
\hline Parameter & Frequency & Percent \\
\hline Nypertension & 1 & 9.1 \\
Yes & 10 & 90.9 \\
\hline $\begin{array}{c}\text { Diabetes mellitus } \\
\text { No }\end{array}$ & 9 & 81.8 \\
Yes & 2 & 18.2 \\
\hline
\end{tabular}

Table 2: Distribution of comorbidities in patients

There was a decrease in the 1 -Week postoperative

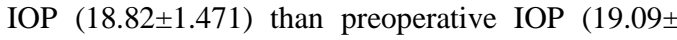
$1.375)$, IOP continued to decrease progressively until the end of the 4-Week follow-up period (11.09 \pm 1.30) that was lower than preoperative and one-week postoperative. However, the decrease in the IOP preoperatively and postoperatively wasn't statistically significant (Table 3 ). 


\begin{tabular}{|c|c|c|c|c|c|}
\hline IOP & Preoperative & 1Week post & 4 Week post & \multicolumn{2}{|c|}{ Pairwise comparison } \\
\hline Range & $17-21$ & $16-21$ & $16-20$ & $Z 1=-1.73$ & $P 1=0.083$ \\
\hline Mean \pm SD & $19.09 \pm 1.375$ & $18.82 \pm 1.471$ & $18.73 \pm 1.272$ & $\begin{array}{l}Z 2=-1.63 \\
Z 3=-0.37\end{array}$ & $\begin{array}{l}P 2=0.102 \\
P 3=0.705\end{array}$ \\
\hline & & & & & \\
\hline
\end{tabular}

Z1, P1: Preoperative VS 1Week post, Z2, P2: Preoperative VS 4 Week post, Z3, P3: 1Week post VS 4 Week post

Table 3: Preoperative IOP versus one week and four weeks postoperatively

There was a significant reduction in one-week postoperative BCVA in logMar $(1.064 \pm 0.258)$ than preoperative $(1.245 \pm 0.221)(P=0.003)$. BCVA in logMar continued to improve progressively until the end of the four-week follow-up period $(0.718 \pm 0.316)$ that was statistically significantly lower than preoperative $(P=0.003)$ and oneweek post-operative $(P=0.003)$ (Table 4$)$, (figure3).

\begin{tabular}{|c|c|c|c|c|c|}
\hline BCVA in logMar & Preoperative & 1Week post & 4 Week post & \multicolumn{2}{|c|}{ Pairwise comparison } \\
\hline Range & $0.90-1.50$ & - $\quad 1.4$ & $0.30-1.20$ & \multirow{2}{*}{$\begin{array}{l}Z 1=-2.98 \\
Z 2=-2.96 \\
Z 3=-3.02\end{array}$} & \multirow{2}{*}{$\begin{array}{l}\mathrm{P} 1=0.003^{*} \\
\mathrm{P} 2=0.003^{*} \\
\mathrm{P} 3=0.003^{*}\end{array}$} \\
\hline Mean \pm SD & $1.245 \pm 0.221$ & $1.064 \pm 0.258$ & $0.718 \pm 0.316$ & & \\
\hline
\end{tabular}

Z1, P1: Preoperative VS 1Week post, Z2, P2: Preoperative VS 4 Week post, Z3, P3: 1Week post VS 4 Week post

$$
* \text { : p value }<0.05 \text { is significant }
$$

Table 4: Preoperative BCVA in logMar versus one week and four weeks postoperatively

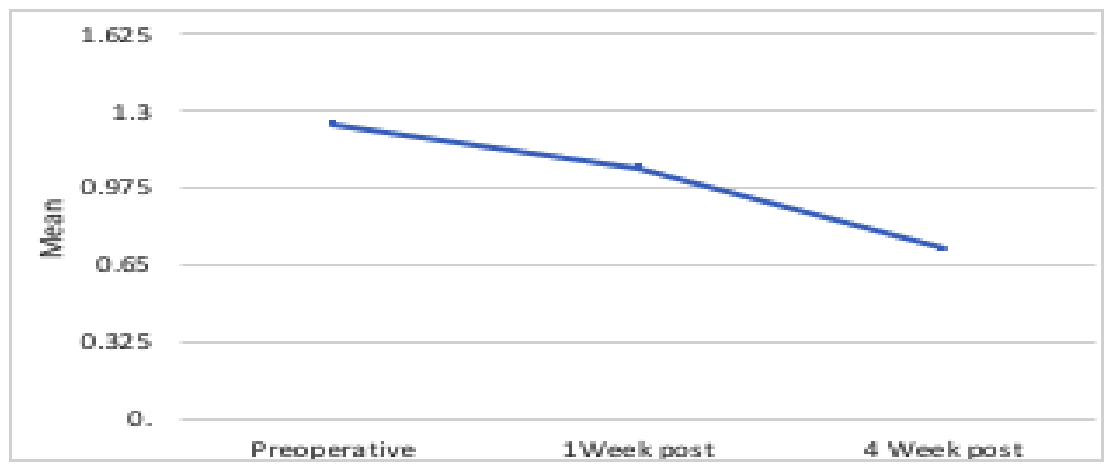

Fig. 3: Preoperative BCVA in log Mar versus one week and four weeks postoperatively

There was a statistically significant decrease in the four-week postoperative CMT $(357.73 \pm 133.094)$ than preoperative CMT (497.27 \pm 225.420$)(P=0.003)$ (Table 5), (figure 4).

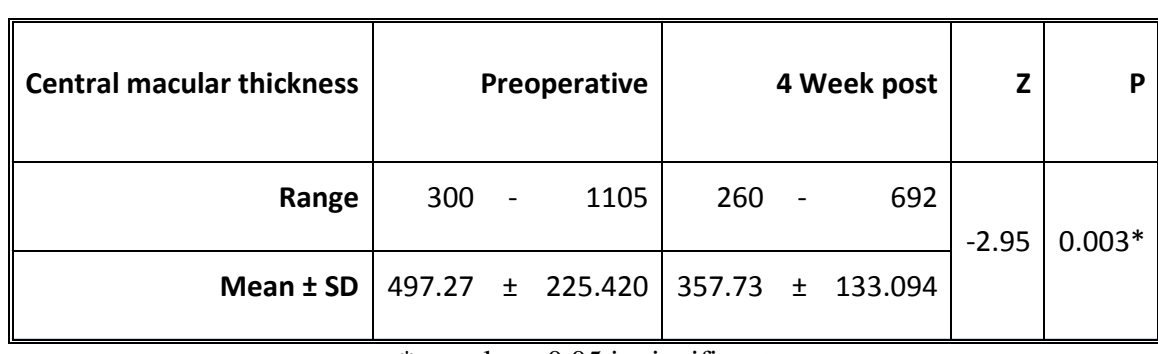

*: $\mathrm{p}$ value $<0.05$ is significant

Table 5: Preoperative CMT versus four weeks postoperatively 


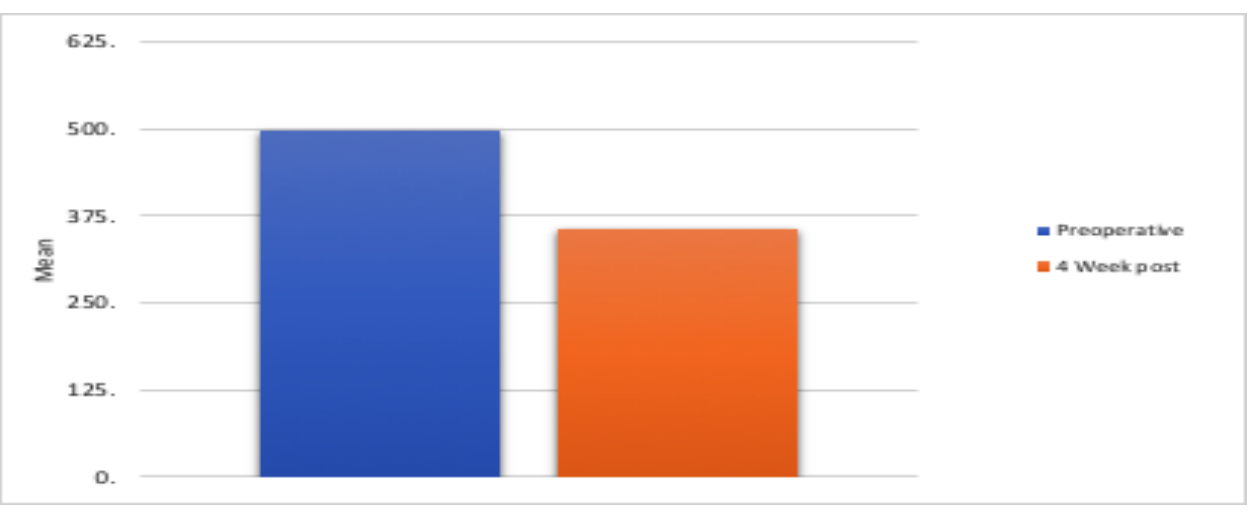

Fig. 4: Preoperative CMT versus four weeks postoperatively
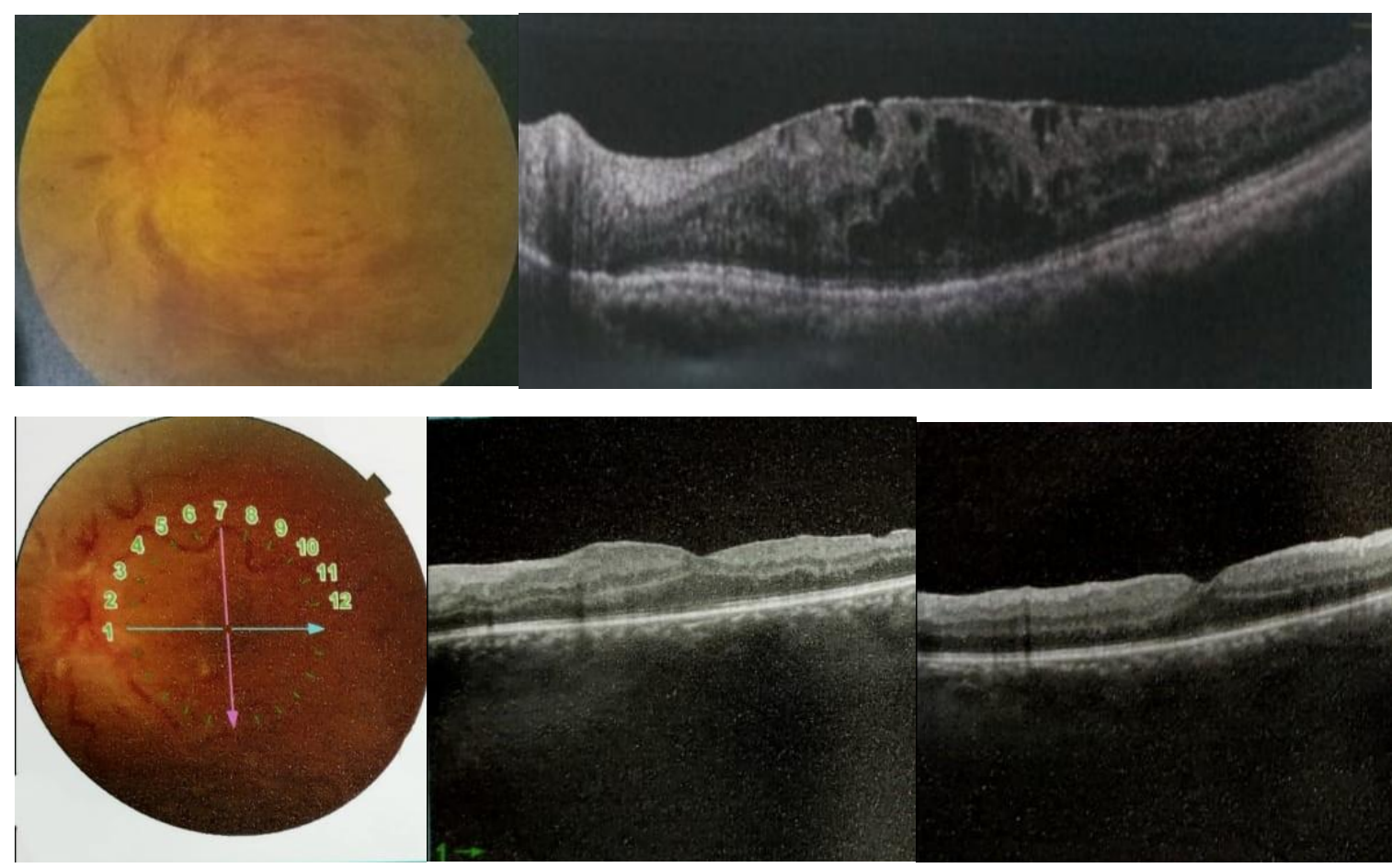

Fig. 5: Case 1: (A); Preoperatively, patient with CRVO with ERM together with macular edema. (B); Postoperatively, the macular edema markedly regressed.

\section{DISCUSSION}

The value of vitrectomy in CRVO includes improved retinal oxygenation, decreased VEGF levels and increased fluid exchange between the vitreous and the retina.

ILM peeling procedure ensures complete removal of epiretinal tractions helping macular edema resolution. ${ }^{8}$ It also improves fluid exchange between the vitreous and the retina. ${ }^{9}$

Multiple studies reported the structural and functional effectiveness of vitrectomy with ILM peeling for macular edema in the eyes with CRVO. Moreover, some recorded that macular edema decreased without visual improvement. ${ }^{10}$

Our finding showed that BCVA in logMar improved progressively till four-week postoperative that was statistically significantly lower than preoperative and one-week post-operative. Also, CMT four-week postoperative was significantly lower than preoperative CMT.

These findings supported by study of Sato et al. ${ }^{11}$ who found that vitrectomy with ILM peeling for nonischemic or ischemic BRVO was efficient in enhancing vision improvement and foveal anatomy resulting in a less number of ME relapse.

The European VitreoRetinal Society ME research has shown the effectiveness of various lines of management of CRVO combined with macular edema. It involved 358 cases, Vitrectomy combined with ILM peeling improved vision better than other therapeutic measures. ${ }^{12}$

Also, DeCroos FC et al. ${ }^{13}$ conducted a study on twelve patients with CRVO in whom pars plana vitrectomy was done with PRP and ILM peeling. This study showed anatomical improvement in 
central foveal thickness without statistically significant visual acuity improvement.

Another study by Shirakata et al. ${ }^{14}$ revealed that central retinal thickness decreased significantly postvitrectomy for ischaemic vein occlusion after 6 months $(p=0.024)$ without significant improvement in VA in postoperative period $(14.7 \pm 11.6$ months $)$.

limitations to this research involved the small sample size making it impossible to prove that this maneuver improved the visual acuity also.

\section{CONCLUSION}

Vitrectomy combined with ILM peeling with intravitreal ranibizumab injection showed anatomical efficacy for ME in eyes with CRVO associated with ERM. Also, there was significant concomitant improvement in VA.

\section{REFERENCES}

1. Hayreh SS. Central retinal vein occlusion. Ocular Vascular Occlusive Disorders 2015 (pp. 621-743). Springer, Cham.

2. Ashraf M, Souka AA, Singh RP. Central retinal vein occlusion: modifying current treatment protocols. Eye. 2016 Apr;30(4):505-14.

3. Mir TA, Kherani S, Hafiz G, Scott AW, ZimmerGaller I, Wenick AS, Solomon S, Han I, Poon D, He L, Shah SM. Changes in retinal non-perfusion associated with suppression of vascular endothelial growth factor in retinal vein occlusion. Ophthalmology. 2016 Mar 1;123(3):625-34.

4. Xiao W, Chen X, Yan W, Zhu Z, He M. Prevalence and risk factors of epiretinal membranes: a systematic review and meta-analysis of populationbased studies. BMJ open. 2017 Sep 1;7(9):e014644.

5. Marticorena J, Romano MR, Heimann H, Stappler T, Gibran K, Groenewald C, Pearce I, Wong D. Intravitreal bevacizumab for retinal vein occlusion and early growth of epiretinal membrane: a possible secondary effect?. British journal of ophthalmology. 2011 Mar 1;95(3):391-5.

6. Ercalik NY, Imamoglu S, Kumral ET, Yenerel NM, Bardak H, Bardak Y. Influence of the epiretinal membrane on ranibizumab therapy outcomes in patients with diabetic macular edema. Arquivos brasileiros de oftalmologia. 2016 Dec;79(6):373-5.

7. Stefansson E. Physiology of vitreous surgery. Graefes Arch Klin Exp Ophthalmol. 2009;247:14763.

8. Kumagai K, Furukawa M, Ogino N, Larson E, Uemura A. Long-term visual outcomes after vitrectomy for macular edema with foveal hemorrhage in branch retinal vein occlusion. Retina. 2007;27(5):584-8.

9. Josifova T, Schneider U, Henrich PB, Schrader W. Eye disorders in diabetes: potential drug targets. Infect Disord Drug Targets. 2008;8(2):70-5.

10. Baharivand N, Hariri A, Javadzadeh A, Heidari E, Sadegi K: Pars plana vitrectomy and internal limiting membrane peeling for macular edema secondary to retinal vein occlusion. Clin Ophthalmol 2011;5:1089-93.

11. Sato S, Inoue M, Yamane S, Arakawa A, Mori M, Kadonosono K. Outcomes of microincision vitrectomy surgery with internal limiting membrane peeling for macular edema secondary to branch retinal vein occlusion. Clin Ophthalmol. 2015;9:43944.

12. Adelman R, Parnes A, Michalewska Z, Parolini B, Boscher C, Ducournau D: Strategy for the management of diabetic macular edema: the European VitreoRetinal Society macular edema study. Biomed Res Int. 2015:352-487.

13. DeCroos FC, Shuler RK Jr, Stinnett S, Fekrat S. Pars plana vitrectomy, internal limiting membrane peeling, and panretinal endophotocoagulation for macular edema secondary to central retinal vein occlusion. Am J Ophthalmol. 2009;147:627-33.

14. Shirakata Y, Fujita T, Nakano Y, Shiraga F, Tsujikawa A. Pars plana vitrectomy combined with internal limiting membrane peeling in treating persistent macular edema after anti-vascular endothelial growth factor treatment in cases of ischemic central retinal vein occlusion. Case reports in ophthalmology. 2016;7(1):1-8. 